\title{
A rapid assessment of Bolivian and Ecuadorian montane avifaunas using 20-species lists: efficiency, biases and data gathered
}

\author{
BENT OTTO POULSEN, NIELS KRABBE, AMY FROLANDER, MARCELO \\ B. HINOJOSA and CARMEN O. QUIROGA
}

\section{Summary}

Tropical forests are disappearing very rapidly, so there is often not time for thorough quantitative studies. It therefore becomes increasingly important to use rapid, reliable and informative methods which are also adjusted to tropical logistic constraints. In this paper we use data from seven dry and semi-humid temperate forest patches in Bolivia and three humid, temperate forests in Ecuador to estimate the efficiency, potential biases and the amount of information obtained by the 20-species list method, which we applied in a rapid assessment of avian species richness. Even when used without any standardizations, 20-species lists produce more data than simple species lists, particularly on the amount of survey effort, the order of species richness, the relative abundances of species and the $\alpha$-diversity index. This approach precludes comparisons with lists from other sites. However, when applied with standardization of area, altitude and effort, the method is neither easier to use nor superior to point counts (based upon vocalizations) in combination with dawn chorus tape-recordings. In species-poor habitats, it is more appropriate to use lists of fewer species. The method is recommended due to its simplicity and the increased quantity of information produced, but it requires a reasonable amount of observer competence and is therefore unfit for use by people ignorant of local avifaunas.

\section{Introduction}

Standardized bird count and census methods such as territory mapping, line transects and point counts are widely used as sole methods to record birds in holarctic habitats (Holmes et al. 1986, Tomialojc and Wesolowski 1990, Bibby et al. 1992). In open, managed forests with low richness, these methods are highly effective, except for nocturnal species (e.g. owls), crepuscular species (e.g. rails, nightjars) and low-density species (e.g. raptors) for which other methods are available (Bibby et al. 1992).

However, in the tropics several problems arise with these methods when species-rich, complex and heterogeneous habitats are investigated (Terborgh et al. 1990). First, in tall lowland forests, the canopy birds are very difficult to study without special, complicated climbing equipment or access to a watch tower. Second, the access to high-altitude habitats is often impeded by the steep 
inclination, low twining trunks and heavy cover of epiphytes, which means that for example the point count method must be modified (Poulsen and Krabbe in press). Furthermore, tropical forest ecosystems contain several guilds of birds which are poorly represented or lacking in high latitude forests; obligate army-ant followers, mixed-species flock participants, wide-ranging obligate frugivores and trap-lining nectarivores are all difficult to record with a single conventional method, because the birds do not sing in these associations and visual encounters are rather infrequent due to a clumped distribution of the birds. Another main problem in many tropical surveys is the lack of personnel familiar with local voices, species or even hand-held birds (Remsen 1994).

One highly effective survey technique in the tropics is tape-recording the dawn chorus and identifying birds by their vocalizations (Parker 1991, Remsen 1994), but the efficiency of this method is very season-dependent. In the tropics, many species breed outside the main season and are therefore not very vocal during this latter period (Oniki and Willis 1982a,b, 1983). To cope with the sum of such problems, it is often necessary to combine different methods like mist-netting, tape-recordings and observations (Poulsen 1994, Remsen 1994) to cover the whole avifaunal spectrum in tropical communities.

As a consequence of the fast disappearance of forests (U.N.F.A.O. 1993, Dale et al. 1994), time does not allow thorough quantitative studies. It therefore becomes increasingly important that methods adjusted to tropical logistic constraints are also rapid, reliable and informative about community characteristics. Simple lists of species are difficult to use for a comparison of sites, since it is unknown to what extent lists of different length reflect different efforts. Thus a standardized rapid assessment method is necessary or at least a procedure where the effect of effort can be taken into account. Another alternative would be a "key species" approach where a small number of important species are selected employing a census method specifically designed for them.

In the present paper, we estimate the efficiency, potential biases and the amount of information obtained from the 20-species list method recommended by MacKinnon and Phillipps (1993). We apply the method in a rapid assessment context using avifaunal data from seven dry and semi-humid temperate forest patches in Bolivia and data from three humid, temperate forests in Ecuador.

\section{Study areas}

From February to April 1995, we investigated the avifaunas of six remnant dry and semi-humid forest patches in the temperate zone of Chuquisaca Department and one dry forest in the immediately adjacent Potosí Department, Bolivia (Table 1). The altitudes, areas and efforts varied from site to site: (1) west of Tarabuco, a patch of dry Polylepis tomentella (Rosaceae) woodland (Kessler 1995); (2) Palmarcito, a stand of the endemic palm Parajubaea torallyi (Palmae) intermixed with evergreen Podocarpus (Podocarpaceae) and deciduous forest along a permanent stream. The palms were bordered below by extensive dry Acacia (Mimosaceae) forest and the adjacent brushy slopes were dominated by Dodonaea (Sapindaceae); (3) north of Sopachuy, patchy, semi-humid, but mostly deciduous forest, including some Alnus (Betulaceae) and intermixed with 


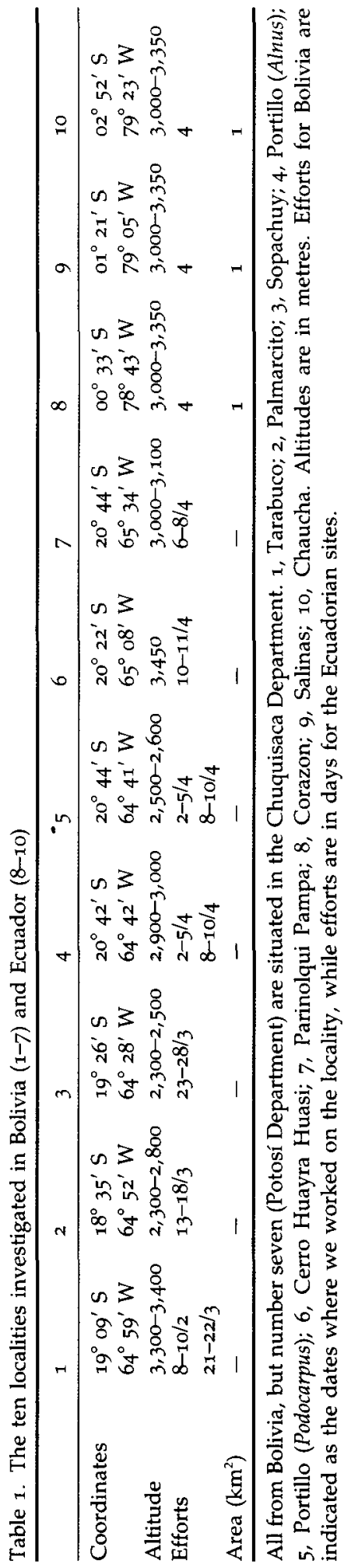


many Podocarpus trees; (4) near Portillo, disturbed Alnus fragments and dispersed, old trees of Polylepis (Rosaceae); (5) near Portillo, a Podocarpus fragment was visited in the same period in April as the Alnus forest. We split the team into two groups to cover both habitats simultaneously; (6) Cerro Huayra Huasi, Polylepis tomentella dwarf woodland (Kessler 1995) on nearly bare soil in a very dry region; (7) Parinolqui Pampa an isolated tract of dry, thorny Prosopis ferox (Mimosaceae) woodland on level and slightly undulating ground.

From January to February 1995, we investigated the avifaunas of three temperate cloud forests on the Andean west slope of Ecuador (Table 1): (8) Corazon, primary, disturbed primary, secondary and bamboo cloud forest; (9) NW of Salinas village, the vegetation at Salinas was similar to that at Corazon; (10) near Chaucha village, the vegetation differed mainly from the two other sites in lacking extensive bamboo areas and in having many Oreocallis (Proteaceae) and Clusia (Clusiaceae) trees.

\section{Methods}

Contrary to the situation in Bolivia, size of area, altitude and survey efforts were all standardized in Ecuador (Table 1 ).

Data were collected by moving around along paths, pastures and through closed forest (where possible) covering the area and altitudinal gradient as homogeneously as possible. As most species were registered by vocalization, successive recordings were made of simultaneously singing/calling individuals and/or of vocalizations widely separated in space.

The first 20-species list is obtained by listing the first 20 species seen. To avoid biases, it is essential to apply names to species that are not confidently identified at first (MacKinnon and Phillipps 1993). When the lists were obtained separately (we made some walks by turns), they were joined subsequently according to the time of day. The number of new species in the first list is 20 . A second list of 20 species will contain repetitions as well as some species which are new compared with the first list. In the following 20-species lists, the increments of new species decline, and eventually level out. If the new species in each list are marked with an asterisk, they are easier to count when the accumulation list of new species is made subsequently (Table 2). The new species in each list are the basis for making the species accumulation graphs (see Figure 1).

Many open-country species were present in localities with open Polylepis woodland. We therefore separated the accumulation of species in a forest-, a total-and a Polylepis-species graph to distinguish between the presence of these bird categories. Polylepis species are birds normally encountered in association with Polylepis trees (Fjeldså and Krabbe 1990). At Palmarcito and Sopachuy, we also isolated the restricted-ranges species (RRS) (Figure I) (ICBP 1992) to investigate the development of the accumulation curve for such "key species".

MacKinnon and Phillipps (1993) recommended 20-species lists on the basis of their experience in South-East Asia. However, we discovered that high-altitude and/or dry habitats in Bolivia are so poor in species that, in some locations, 10-species lists (Figures 1 and 2) are better.

A special technique of making notes provides more opportunities for analysing the data subsequently. Although space consuming, we recommend that all individuals recorded are put on paper separately, except when several 
Table 2. Accumulation list of new species from Sopachuy, Department of Chuquisaca, Bolivia

\begin{tabular}{lcccccccccccccccc}
\hline $\begin{array}{l}\text { Number of } \\
\text { 20-species list }\end{array}$ & 1 & 2 & 3 & 4 & 5 & 6 & 7 & 8 & 9 & 10 & 11 & 12 & 13 & 14 & 15 & 16 \\
\hline $\begin{array}{l}\text { Accumulated new } \\
\text { species }\end{array}$ & 20 & 9 & 6 & 6 & 4 & 2 & 2 & 1 & 2 & 2 & 0 & 0 & 1 & 1 & 0 & 2 \\
\hline $\begin{array}{l}\text { Number of } \\
\text { 20-species list }\end{array}$ & 17 & 18 & 19 & 20 & 21 & 22 & 23 & 24 & 25 & 26 & 27 & 28 & 19 & 30 & 31 \\
\hline $\begin{array}{l}\text { Accumulated new } \\
\text { species }\end{array}$ & 0 & 0 & 1 & 1 & 0 & 4 & 0 & 0 & 0 & 0 & 1 & 2 & 0 & 0 & 0 \\
\hline
\end{tabular}

individuals of a species are observed/heard simultaneously. It offers the opportunity for assembling lists from various observers and changing the size of the lists freely. Otherwise one has to decide in advance, whether a 10-, 15or 20-species list is the most appropriate method for a specific locality.

We also extracted relative abundances for each species by counting how many times a species was recorded in the total set of 20-species lists. The abundance distributions were fitted to an appropriate mathematical model by calculating the expected number of observations in each abundance class and comparing that with the number of observations actually recorded in 20-species lists using a chi-square goodness of fit test (Kempton and Taylor 1974, Taylor et al. 1976, Magurran 1988, Krebs 1989).

\section{Results}

\section{Accumulation graphs}

The accumulated number of species was plotted as a function of the number of 20-species lists (Figure 1). The total-species accumulation graph for Tarabuco (Figure 1) continues to increase throughout the study period. The graph showing only forest species increases slowly in an almost linear fashion, while the graph showing Polylepis species levels out very rapidly. The Cerro Huayra Huasi site shows a similar pattern to Tarabuco, except that the forest-species accumulation graph seems to approach the form of an asymptote. Despite an addition to list number 19 of three species at Palmarcito, this graph and the Sopachuy graph seem to approach a ceiling asymptotically. At the same two sites, both RRS-curves quickly reach a certain low level, which is constant over many 20-species lists. The accumulation of species at Parinolqui Pampa has stopped at 29 species and the last six lists do not add new species. Two forest fragments were investigated at Portillo. Both the Alnus and Podocarpus fragments have few lists, but both graphs appear to approach an asymptote. The species accumulation graphs from Corazon and Chaucha almost level off smoothly, while the Salinas curve increases stepwise towards a ceiling at approximately the same level.

\section{Frequency graphs}

The relative abundance of each species was depicted together with the expected values in a frequency distribution for each of the localities (Figure 2). The 
frequency-distribution graphs from all sites display a somewhat similar pattern. All localities were described satisfactory by the log-series mathematical model (Tarabuco, $\chi^{2}=15.5, d f=45, P>0.05$; Cerro Huayra Huasi, $\chi^{2}=8.6, d f=41$, $P>0.05 ;$ Palmarcito, $\chi^{2}=16.5, d f=71, P>0.05$; Sopachuy, $\chi^{2}=74.2, d f=$ 67, $P>0.05$; Parinolqui Pampa, $\chi^{2}=10.4, d f=28, P>0.05$; Portillo (Alnus), $\chi^{2}=7.0, d f=43, P>0.05$; Portillo (Podocarpus), $\chi^{2}=16.4, d f=38, P>0.05 ;$ Corazon, $\chi^{2}=61.2, d f=70, P>0.05$; Salinas, $\chi^{2}=82.7, d f=64, P>0.05$; Chaucha, $\left.\chi^{2}=54.5, d f=64, P>0.05\right)$, which predicts a small number of abundant species, a long "tail" of rare species and the one-individual class to be the largest (Fisher et al. 1943).

\section{The a-diversity index}

From the log-series calculations an index of $\alpha$ - diversity was obtained (Magurran 1988, Krebs 1989): Tarabuco 22.4 $(n=152, S=46)$, Cerro Huayra Huasi $18.9(n=155, S=42)$, Palmarcito $27.3(n=353, S=72)$, Sopachuy 20.4 $(n=552, S=68)$, Parinolqui Pampa 12.1 $(n=121, S=29)$, Portillo (Alnus) 27.4 ( $n=109, S=44)$, Portillo (Podocarpus) $21.2(n=112, S=39)$, Corazon 25.1 $(n=399, S=71)$, Salinas $22.4(n=386, S=65)$ and Chaucha $24.2(n=330$, $S=65)$. $S$ denotes the number of species and $n$ the total number of observations in 20-species lists.

\section{Discussion}

\section{Species accumulations}

The Tarabuco site obviously holds more species of both forest and open land (i.e. total minus forest-species) than recorded. At Cerro Huayra Huasi more species associated with open land can be expected, whereas few forest species will be added if the survey continues. In contrast to this, most Polylepis species were recorded rapidly in both places. This is in accordance with results from Polylepis forests obtained with another method by Fjeldså (1993). Thus, while short-term studies are insufficient for recording the total number of species, they may be fairly adequate in low-diversity areas for the sedentary birds that are particular to the habitat in question (Fjeldså 1993). Such species may also have a higher priority in conservation than more broadly adapted species. Other subdivisions, such as threatened, near-threatened species (Collar et al. 1992) or restricted-range species (ICBP 1992), may also be appropriate when evaluating conservation priorities. The RRS-curves from Palmarcito and Sopachuy both contain more 20-species lists than the Polylepis-curves from Tarabuco and Cerro Huayra Huasi, but display more or less the same course as the latter curves.

The almost asymptotic species-accumulation graphs from Palmarcito, Sopachuy, Parinolqui Pampa, Corazon, Salinas and Chaucha present reasonable estimates of the magnitude of species-richness associated with these habitats. Only a few additional species can be expected. Two of the three new species recorded in list number 19 at Palmarcito were big, rare raptors, which leads us to consider the sudden increase in species to be accidental. Despite the few lists obtained at Portillo, the homogeneous stands of the Alnus and Podocarpus 
fragments and the isolation from other forests warrant an interpretation of an almost complete species account. Accordingly, both habitats accomodate a richness around 40-50 species.

In poorly surveyed sites, which may be important for conservation purposes, reporting a number of species for comparison with other sites may be misleading without some information about the effort used or how far from complete such lists are. Either the rates of accumulation of new species or an estimate of the percentage of the total number (the approximate position of the ceiling) is necessary to make meaningful comparisons (Soberón and Llorente 1993).

\section{Rapid assessment}

The species-accumulation graphs may thus present information on the level of total community richness (Figure 1 ), the time needed to reveal the majority of species (Figure 1 ), the prevalence of habitat specialists and species with restricted ranges (Figure 1). We used from two to six days at each site (Table 1), and one locality was obviously sufficiently surveyed in two days (Parinolqui Pampa), while others required at least six days (Palmarcito and Sopachuy). Such a difference in use of time is difficult to assess in advance. Being a compromise with the urgency of wildlife evaluations, a rapid assessment has the advantage of recording the majority of species and at the same time avoiding most of the rare visitors and vagrants passing through the community during a long-term study. Such transient species tell us very little about the conservation value of a site, but blur the distinction between themselves and resident rare species.

\section{Relative and absolute abundances}

Although all frequency distributions were satisfactorily described by the log series mathematical model, there is a tendency for more moderately common species and a moderate "tail" of low-abundance species compared with some species-rich humid, tropical forests, where very few species are abundant and the vast majority of species are scarce (Okia 1976, Silva and Constantino 1988, Poulsen 1994). This tendency is visualized by the gaps between the observed and expected frequencies in the region of moderately common species (Figure 2). We suspect that these discrepancies might be caused by differences in humidity (which influences species-richness), the number of species present and/or the difference in methods applied. The abundances from the three studies above were obtained by mist-nets or counts and thus represent absolute numbers with no upper limit. The frequency distributions created by us have a ceiling, which seems to inflate the difference between the observed and expected frequencies in this end of the distribution (Figure 2). This creates high chi-square values, which together with similar high chi-square values from the region of moderately common species moves the total chi-square value in the direction of significance. The importance of these phenomena needs to be investigated in more detail. 

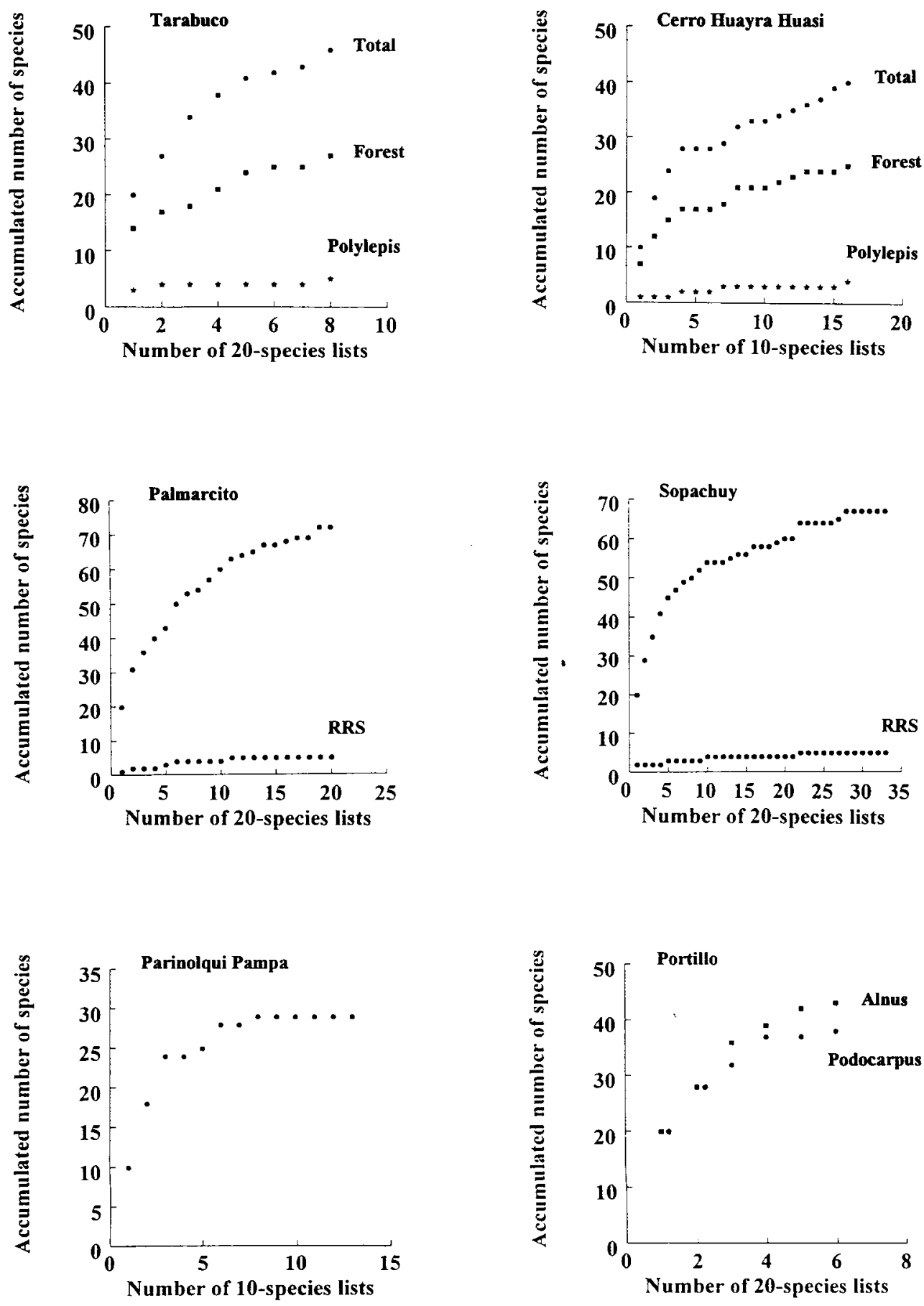

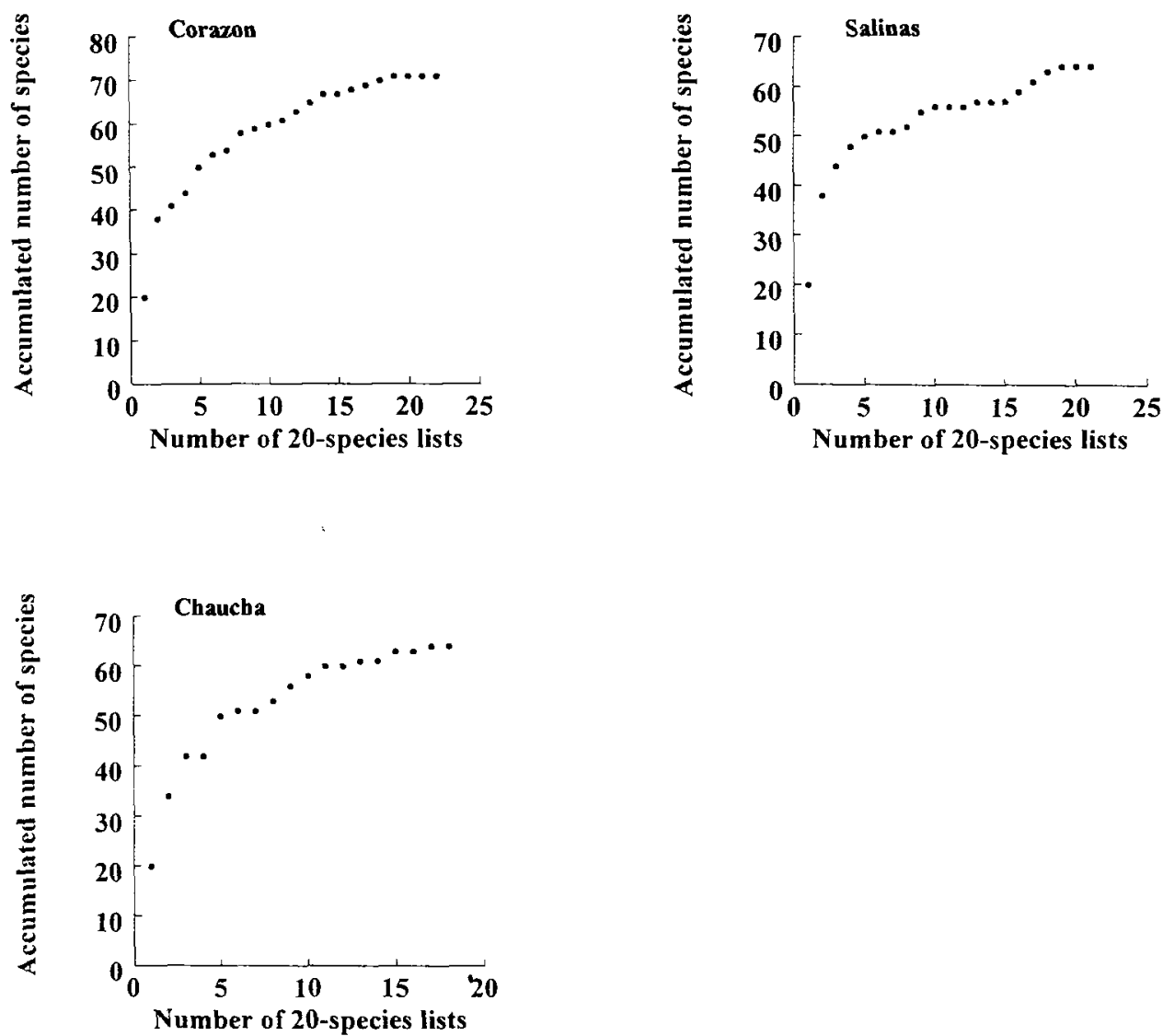

Figure 1. Species-accumulation graphs for six localities in Chuquisaca and Potosí Departments, Bolivia, and three localities on the Andean western slope of Ecuador. The accumulated number of species is depicted as a function of the number of $10-$ and 20-species lists obtained. Total $=$ total number of species including species from open areas; Forest, species occuring in forest only; Polylepis, species restricted to Polylepis forest; RRS, restricted-range species (see ICBP 1992) occuring on the locality.

\section{Even/uneven sampling}

Uneven sampling efforts destroy comparability of species lists from different sites, but an appropriate compromise is to employ the relative abundances of species (Harrison and Martinez 1995). Despite the use of relative abundances, a greater sampling area or more research efforts will produce more species, which will displace the ceiling of the species accumulation curve and thus influence an $\alpha$-diversity index. If such an index of diversity (like $\alpha$ obtained from the log-series distributions) is applied, it is useful only in relation to other indices calculated in the same manner (Harrison and Martinez 1995). These conditions 
B. O. Poulsen et al.
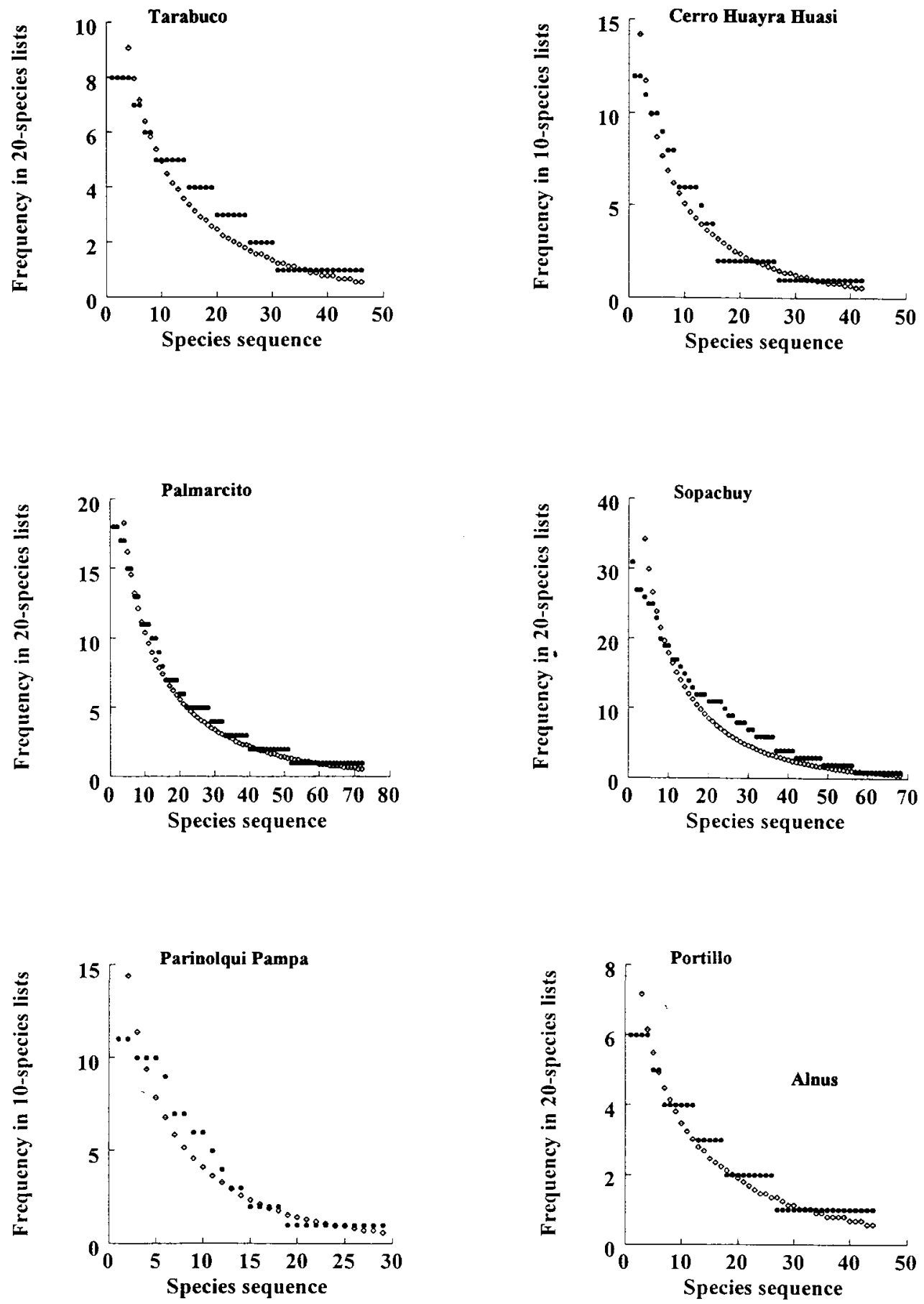

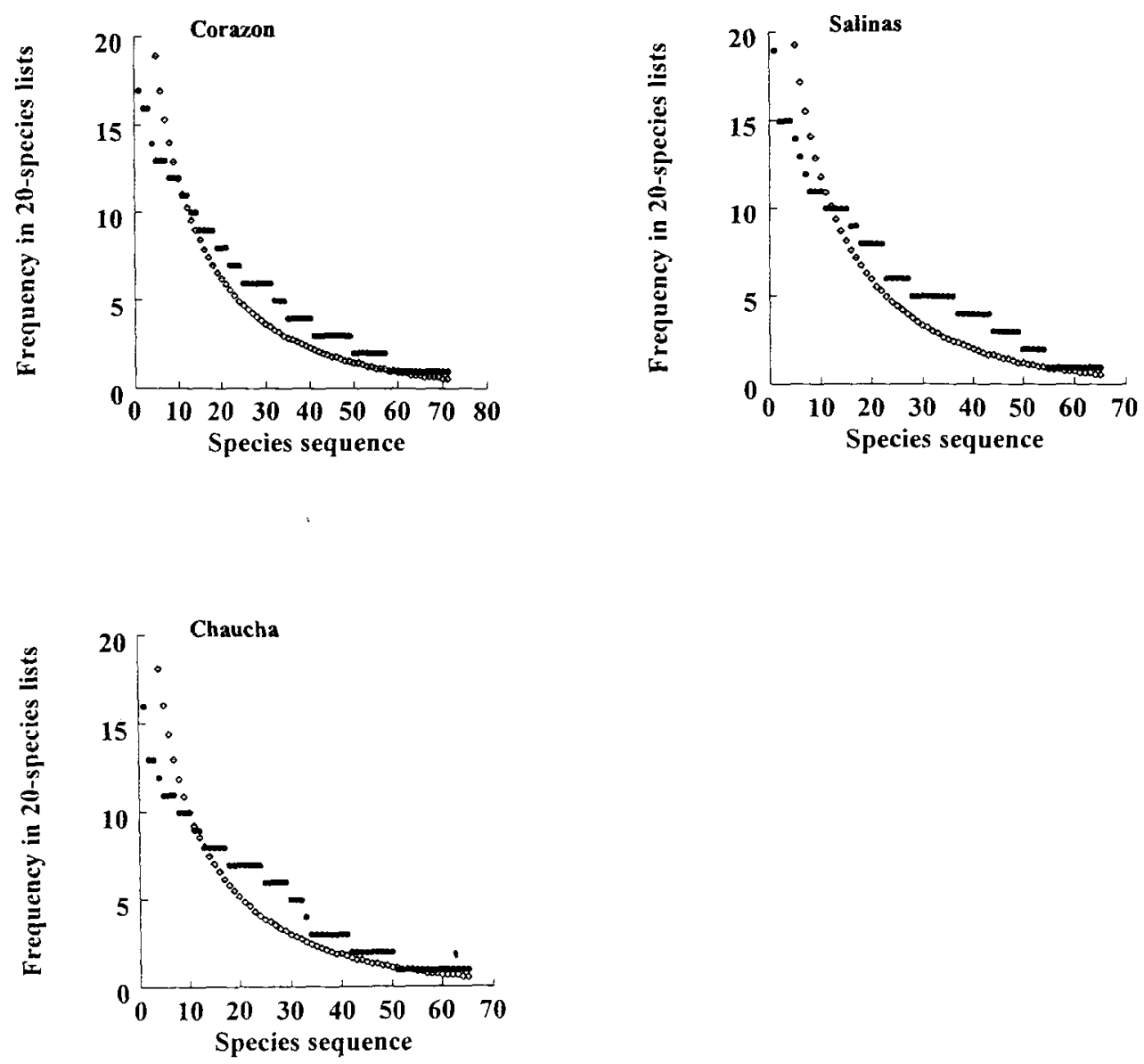

Figure 2. Frequency-distribution graphs for six localities in Chuquisaca and Potosí Departments, Bolivia, and three localities on the Andean western slope of Ecuador. Using the log-series model, the expected and actual frequency values in 10- and 20-species lists are depicted against the species sequence. The results for Portillo (Podocarpus) are not depicted. Filled circles, actual values; hatched rhombuses, expected values.

exclude the possibility of comparing the $\alpha$-diversities of our Bolivian sites, but given asymptotic species-accumulation curves, a standardized method and equal efforts, it should be possible to compare the $a$-diversities from the three Ecuadorian sites. These sites appear to be quite similar in $\alpha$-diversity, which is in accordance with our results from the same sites when abundances were obtained as actual numbers in point counts (Poulsen and Krabbe, in press). Kempton and Taylor (1974, 1976) and Taylor et al. (1976) found the log series $\alpha$-index robust and favoured its use even when the underlying speciesabundance pattern was different. In conclusion, frequency distributions present some information about community differences, but are more informative if area, altitude and efforts are standardized. 


\section{Biases}

A potential bias in the method is the accumulation of knowledge of vocalizations in the course of a study and partly the inclusion of this in the lists. MacKinnon and Phillipps (1993) recommend that all species seen should be included in the lists, even if they are not recognized at first, but it is equally important that species heard are also given a temporary name associated with a description of the unknown voice. Otherwise, the relative abundances will be biased in favour of conspicuous species and valuable information will be lost. On the other hand, if mainly singing species are added, the lists will be biased in favour of the most vocal species. It is thus necessary to use a combination of both to minimize the total bias of the method. During the course of a study, one often sees a crepuscular species, and if not, it is possible to use a day to confirm the unidentified but recognized species by the help of replay from a tape-recorder.

Another bias is that some vocalizations simply are overheard or that crepuscular species like some Tinamous (Tinamidae), Puffbirds (Bucconidae), Woodcreepers (Dendrocolaptidae) and Tyrant-Flycatchers (Tyrannidae) only sing 1-3 songs during the first five minutes of light (often well before there is enough light to see them) (Parker 1991), and therefore are easily missed. However, it is possible to design the recording activity to reduce the latter problem, although the crepuscular species will remain quantitatively underestimated.

To compile lists with a minimum of bias, the method therefore requires survey personnel that know the majority of species or all main groups, and at least some of the more common voices encountered. This will create the necessary basis for picking up quickly the "new" voices.

\section{Timed species-counts}

Pomeroy and Tengecho (1986) used another simple method for surveying avifaunas. In contrast to the 20-species list method, their "Timed Species-count" (TSC) method was applied in a large region, in open habitat and during a long time-span. However, they also used standardized area and effort by covering $151-\mathrm{km}^{2}$ sites distributed over $40,000 \mathrm{~km}^{2}$. Each site was visited 15 times over all seasons and times of day and counted for one hour each time. Thus, we use in our standardized approach approximately 40 hours of registration concentrated on four consecutive days, while the TSC method uses 15 hours at each site during at least one year. The TSC method could probably also be used in forest, but it is inherent in the method that the counts of one hour each need to be distributed over a longer period of time in order to produce a reasonable amount of data for making species accumulation curves. There is no sense in working only 15 hours during a stay of 4 days. However, if the TSC method is expanded to include more than 15 one-hour counts in four days, it will resemble the 20-species list method except that the data on the $x$-axis of the species accumulation curve will be cumulative time instead of cumulative 20-species lists. However, in its present form, the strength of the TSC method lies in a more thorough coverage of the total avifauna, while the advantage of the 20species list method is its applicability in rapid assessment surveys. Both methods must be considered simple, but Pomeroy and Tengecho (1986) also 
stress that the researchers need to be reasonably familiar with the region before they start, even when the fact is that most species in open areas are seen and not only heard as in closed forest.

Pomeroy and Tengecho (1986) estimate the total number of species by calculating the equation of the regression line when the number of additional species is depicted as a function of the cumulative number of species. The number of additional species becomes zero where the straight line crosses the $x$-axis. This point is the estimated number of species for the site. The same calculation could probably be applied to the 20-species list method, but it leads to underestimates of richness (Pomeroy and Tengecho 1986), and is not necessary when asymptotic curves are produced.

\section{Conclusions}

Besides producing a list of species, the 20-species list method is also suitable for judging (a) when a site is adequately surveyed, (b) the magnitude of the species richness, (c) the relative abundances of each species and (d) an $\alpha$-index of diversity. Twenty-species lists are biased like any other bird count, but not more than other methods. We suggest that vocalizations be combined with observations, which requires a concentrated and careful transcription of data. In species-poor areas, lists of fewer species should be used. Even when used without any standardizations, 20-species lists produce more data than simple species lists, but when applied with standardized area, altitude and efforts, the method is neither easier to use nor superior to point counts (based upon vocalizations) in combination with dawn chorus tape-recordings (Poulsen and Krabbe, in press).

The method is recommended due to its immediate simplicity and the increased amount of data produced, but it requires a reasonable amount of observer competence and is therefore unfit for use by people ignorant of local avifaunas. If more widely used by skilled birdwatchers, the method will provide a basis for extracting better data from the many low-information lists produced in numerous travel reports.

\section{Acknowledgements}

This paper was written under a grant from the Center for Research on Cultural and Biological Diversity of Andean Rainforests (DIVA), an interdisciplinary project of collaboration between Universities of Ecuador, Peru, Bolivia and Denmark. We are indebted to the Ministerio de Desarrollo Sostenible y Medio Ambiente and Museo Nacional de Historia Natural (MNHN) for help, permission and encouragement to do research in Bolivia. Special thanks are directed to Omar $O$. Rocha, who spent an immense amount of time helping us to buy a car for the expedition. We are grateful to J. Rabøl, J. M. C. Silva, J. Fjeldså and N. D. Burgess for commenting on and discussing the manuscript. We also thank Mary E. Petersen for revising the English text and commenting on the paper. 


\section{References}

Bibby, C. J., Burgess, N. D. and Hill, D. A. (1992) Bird census techniques. London: Academic Press.

Collar, N. J., Gonzaga, L. P., Krabbe, N., Madroño Nieto, N., Naranjo, L. G., Parker III, T. A. and Wege, D. C. (1992) Threatened Birds of the Americas. Cambridge, U. K.: International Council for Bird Preservation.

Dale, V. H., Pearson, S. M., Offerman, H. L. and O'Neill, R. V. (1994) Relating patterns of land-use change to faunal biodiversity in the central Amazon. Conserv. Biol. 8: 10271036.

Fjeldså, J. (1993) The avifauna of the Polylepis woodlands of the Andean highlands: the efficiency of basing conservation priorities on patterns of endemism. Bird Conserv. Internatn. 3: 37-55.

Fjeldså, J. and Krabbe, N. (1990) Birds of the High Andes. Copenhagen: Zoological Museum, University of Copenhagen and Svendborg: Apollo Books.

Fisher, R. A., Corbet, A. S. and Williams, C. B. (1943) The relation between the number of species and the number of individuals in a random sample of an animal population. J. Anim. Ecol. 12: 42-58.

Harrison, J. A. and Martinez, P. (1995) Measurement and mapping of avian diversity in southern Africa: implications for conservation planning. Ibis 137: 410-417.

Holmes, R. T., Sherry, T. W. and Sturges, F. W. (1986) Bird community dynamics in a temperate deciduous forest: long-term trends at Hubbard Brook. Ecol. Monogr. 56: 201220.

International Council for Bird Preservation (ICBP) (1992) Putting biodiversity on the map: priority areas for global conservation. Cambridge: Burlington Press.

Kempton, R. A. and Taylor, L. R. (1974) Log-series and log-normal parameters as diversity discriminants for the Lepidoptera. J. Anim. Ecol. 43: 381-399.

Kempton, R. A. and Taylor, L. R. (1976) Models and statistics for species diversity. Nature 262: 818-820.

Kessler, M. (1995) Polylepis-Wälder Boliviens: Taxa, ökologie, verbreitung und geschichte. Berlin: J. Cramer.

Krebs, C. J. (1989) Ecological methodology. New York: Harper Collins Publishers.

MacKinnon, J. and Phillipps, K. (1993) A field guide to the birds of Borneo, Sumatra, Java and Bali. Oxford: Oxford University Press.

Magurran, A. E. (1988) Ecological diversity and its measurement. London: Croom Helm.

Okia, N. O. (1976) Birds of the understorey of lake-shore forests on the Entebbe peninsula, Uganda. Ibis 118: 1-13.

Oniki, Y. and Willis, E. O. (1982a) Breeding records of birds from Mànaus, Brazil: Formicariidae to Pipridae. Rev. Brasil. Biol. 42: 563-569.

Oniki, Y. and Willis, E. O. (1982b) Breeding records of birds from Manaus, Brazil, II. Apodidae to Furnariidae. Rev. Brasil. Biol. 42: 745-752.

Oniki, Y. and Willis, E. O. (1983) Breeding records of birds from Manaus, Brazil, IV. Tyrannidae to Vireonidae. Rev. Brasil. Biol. 43: 45-54.

Parker, T. A. III. (1991) On the use of tape-recorders in avifaunal surveys. Auk 108: 443444.

Pomeroy, D. and Tengecho, B. (1986) Studies of birds in a semi-arid area of Kenya, III. The use of "Timed Species- counts" for studying regional avifaunas. J. Trop. Ecol. 2: 231-247.

Poulsen, B. O. (1994) Mist-netting as a census method for determining species richness and abundances in an Andean cloud forest bird community. Gerfaut 84: 39-49.

Poulsen, B. O. and Krabbe, N. (in press) Avifaunal diversity of five high-altitude cloud forests on the Andean western slope of Ecuador: testing a rapid assessment method. J. Biogeogr. 
Remsen, J. V. Jr. (1994) Use and misuse of bird lists in community ecology and conservation. $A u k$ 111: 225-227.

Silva, J. M. C. and Constantino, R. (1988) Aves de um trecho de mata no baixo Rio Guamá - uma reanálise: riqueza, raridade, diversidade, similaridade e preferencias ecologicas. Bol. Mus. Para. Emilio Goeldi, sér. Zool. 4: 201-210.

Soberón M., J. and Llorente B., J. (1993) The use of species accumulation functions for the prediction of species richness. Conserv. Biol. 7: 480-488.

Taylor, L. R., Kempton, R. A. and Woiwod, I. P. (1976) Diversity statistics and the log-series model. J. Anim. Ecol. 45: 255-272.

Terborgh, J., Robinson, S. K., Parker, T. A., Munn, C. A. and Pierpont, N. (1990) Structure and organization of an Amazonian forest bird community. Ecol. Monogr. 6o: 213-238.

Tomialojc, L. and Wesolowski, T. (1990) Bird communities of the primaeval temperate forest of Bialowieza, Poland. In A. Keast, ed. Biogeography and ecology of forest bird communities. The Hague: SPB Academic Publishing.

U. N. Food and Agriculture Organization (F.A.O.) (1993) Forest resources assessment 1990 project: Project findings and recommendations. Rome: F.A.O.

BENT OTTO POULSEN, NIELS KRABBE and AMY FRØLANDER

Centre for Research on the Cultural and Biological Diversity of Andean Rainforests (DIVA), Zoological Museum, University of Copenhagen, Universitetsparken 15, 2100 Copenhagen $D$, Denmark.

MARCELO B. HINOJOSA and CARMEN O. QUIROGA.

Museo Nacional de Historia Natural, Universidad Mayor de San Andres, Casilla 10077, La Paz, Bolivia. 